\title{
House Prices AND ECONOMIC GROWTH in South Africa: Evidence From PROVINCIAL-LeVEL DATA
}

\author{
Beatrice D. Simo-Kengne \\ University of Pretoria \\ Manoel Bittencourt \\ University of Pretoria \\ Rangan Gupta \\ University of Pretoria
}

\begin{abstract}
This paper empirically examines the effect of house price changes on economic growth across provinces in South Africa. The economic impact of house prices is estimated using a panel data set that covers all nine provinces in South Africa from 1996 to 2010. The findings show that when heterogeneity, endogeneity, and spatial dependence are controlled for, house price changes exhibit a significant effect on regional economic growth in South Africa. The paper introduces a seemingly unrelated regression (SUR) specification and shows that spatial effects are highly important in South African housing markets. Moreover, the estimation results suggest that the wealth effect is important at the aggregated level, which contrasts the relevance of the collateral effect found at the regional level.
\end{abstract}

Disparities in growth rates have been widening among South Africa's provinces, which account for significant inequality in the spatial distribution of economic activity (Naude and Krugell, 2006). The four fastest growing provinces averaged an annual per capita growth rate of $2.62 \%$ over the past five years. In contrast, the two slowest growing provinces registered a $1.62 \%$ growth rate on average over the same period. The high growth regions differ in terms of population densities, building construction, personal income, as well as job market conditions. Gauteng and Western Cape are examples of densely populated regions with high house prices that have grown faster over the past five years. Free State is less densely populated and has grown tremendously over the same period, but the house prices are lower and there is a moderate unemployment rate. Conversely, Northern Cape, the slowest growing province, has the highest house price inflation over the past few years (Exhibit 1).

Holly, Pesaran, and Yamaga (2010) state that changes in housing prices have major implications for output and credit market. Also, house prices fluctuate due to job market conditions and relocation costs (Holmes, 2007). It follows that the housing market may stimulate the economy or may trigger economic recession as vindicated by the recent global financial turmoil, which had its roots in the subprime crisis in the United States. However, from the differences in average house price inflation across the regions, it is not clear whether regions experiencing high increases in house 


\section{Exhibit 1}

\section{Characteristics of the Fastest and Slowest Growing Provinces in South Africa, 2006-2010}

\begin{tabular}{llccc}
\hline Provinces & $\begin{array}{l}\text { Real Per Capita } \\
\text { Growth Rate (\%) }\end{array}$ & $\begin{array}{l}\text { Population } \\
\text { Growth (\%) }\end{array}$ & $\begin{array}{l}\text { House Prices } \\
\text { Changes (\%) }\end{array}$ & $\begin{array}{r}\text { Unemployment } \\
\text { Rate Changes (\%) }\end{array}$ \\
\hline Fastest Growers & & & & \\
Gauteng & 2.871 & 0.666 & 7.958 & 3.336 \\
KwaZulu-Natal & 2.753 & 0.521 & 6.865 & -8.978 \\
Eastern Cape & 2.724 & 0.496 & 7.654 & -1.644 \\
Free State & 2.485 & -0.022 & 9.632 & -0.594 \\
Western Cape & 2.302 & 1.094 & 7.086 & 4.547 \\
Average & 2.627 & 0.551 & 7.839 & -0.666 \\
Slowest Growers & & & & -1.078 \\
Northern Cape & 1.366 & 0.981 & 12.352 & 1.205 \\
Mpumalanga & 1.620 & 0.77 & 10.708 & -3.843 \\
Limpopo & 1.741 & 0.955 & 11.289 & -2.117 \\
North West & 1.743 & 0.568 & 9.545 & -1.458 \\
Average & 1.617 & 0.818 & 10.973 & \\
\hline
\end{tabular}

prices grow faster than those experiencing slow increases in house prices. In effect, house prices may simply keep pace with inflation such that house prices in the relatively poorer regions may not be below the cross-regional average as expected. Understanding how economic growth is related to house prices is therefore of considerable value.

In South Africa, housing accounts for $29.40 \%$ of household assets and $21.68 \%$ of total wealth (Das, Gupta, and Kanda, 2011). The permanent income hypothesis asserts that house price inflation increases the expected lifetime wealth of homeowners and hence impacts their desired consumption. This is known as the wealth effect. The collateral effect, on the other hand, postulates that fluctuations in house prices relax homeowners' financial constraints, which may in turn affect their actual consumption. While the wealth effect is immediate, the collateral effect assumes households are financially constrained. Consequently, distinguishing between the wealth effect and the collateral effect of house prices may contribute to understanding which policy measures will be effective in raising growth. For instance, easing borrowing constraints to stimulate the economy may not be efficient if the recession is due to the wealth effect; meaning that "... households voluntarily reduce consumption because they feel poorer" (Miller, Peng, and Sklarz, 2011).

Against this backdrop, this study investigates the effect of house prices on provincial gross domestic product (GDP) in South Africa over the period of 1996 to 2010. South Africa has nine provinces: Eastern Cape, Free State, Gauteng, KwaZulu-Natal, Limpopo, Mpumalanga, Northern Cape, North West, and Western Cape. Exhibit 2 is a provincial map of South Africa. The methodology employed is able to address diverse econometric issues in analyzing house prices using panel data. Specifically, Fixed Effect and Random Coefficient models are used to account for heterogeneity and Generalized Method of Moments (GMM) to control for endogeneity. Spatial

Volume 20, Number 1, 2012 


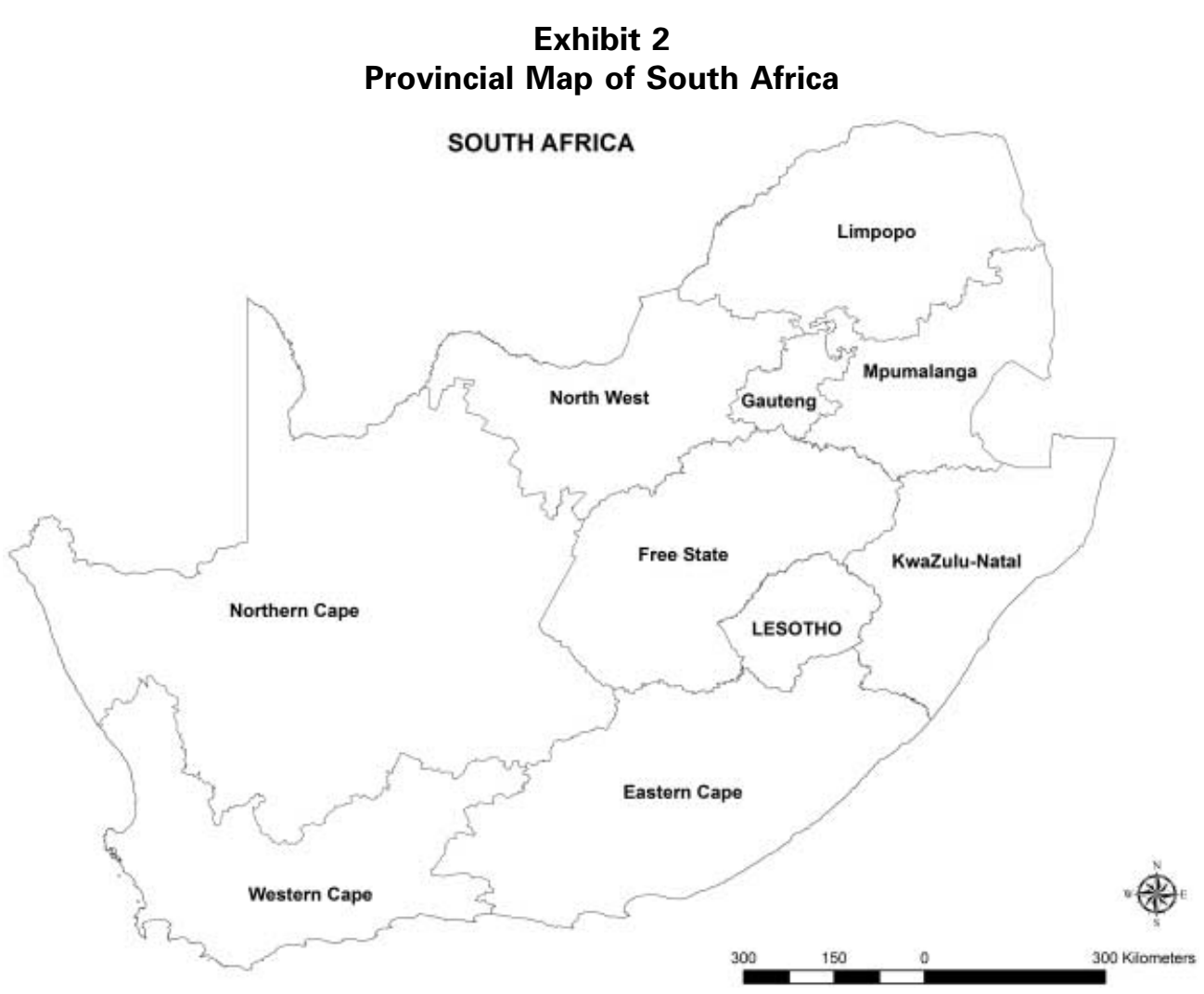

Source: Council for Scientific and Industrial Research (CSIR), Pretoria, South Africa.

dependence, on the other hand, is addressed within an error component framework in which seemingly unrelated regression (SUR) is considered to allow for crossprovincial comparison.

The estimation results from this study provide strong evidence that house price changes significantly and positively affect provincial-level per capita GDP growth, both across and within provinces. The importance of cross-correlation between regions is also established, indicating that economic growth in a province is not only affected by the local house price changes but also by the fluctuations in house prices in other provinces. Further, there is a distinction between collateral effect and wealth effect. As in Campbell and Cocco (2007), collateral effect is captured by the predictable component of house price changes and wealth effect by the unpredictable component of house price changes. While the wealth effect is relevant at the aggregate level, the evidence from cross-sectional variation is mixed. The economic effect of the predictable component of house price changes dominates in five out of nine provinces, whereas the economic effect of the unpredictable component rules four provinces. These variations substantiate the heterogeneity of regional housing markets within the South African economy, indicating the existence of socio-economic imbalances among provinces. 
The rest of the paper is organized as follows: Section 2 provides theoretical motivations for the economic impact of house prices and reviews thereafter the limited evidence of the effect of housing price fluctuations on economic growth. Section 3 describes the data with respect to the measures and transformation of the variables included in the regression. Section 4 discusses the empirical methodology. Section 5 presents the estimation results, and Section 6 concludes.

\section{LiterATURE REVIEW}

Although the economic impact of house prices may be channelled through a variety of transmission mechanisms (Demary, 2009), the literature on housing mainly focuses on the wealth effect and the collateral effect.

Derived from Friedman's Permanent Income Hypothesis, the wealth effect suggests that unexpected house price appreciation is likely to increase the expected lifetime wealth of homeowners and thereby their desired consumption. Since housing accounts for a substantial share of household assets and wealth, house prices inflation would increase the expected lifetime wealth of homeowners. Based on the assumption that homeowners are willing to smooth consumption over their lifetime, the increase in wealth would increase their desired consumption (Miller, Peng, and Sklarz, 2009).

It has recently been argued that a link between house prices and consumption may arise via the collateral effect (Ortalo-Magne and Rady, 2004). When households are financially constrained, house price increases can help relax homeowners' financial constraints, which translate into an increase in credit supply. Since housing wealth can be collateralized, higher house prices enhance the borrowing capacity of homeowners and enable them to borrow and spend more. The rise in credit supply will lower interest rates that may affect actual consumption instead of desired consumption. Therefore, the consumption effect of house price changes relies on the assumption that the actual consumption of constrained households is lower than their desired consumption.

There is an increasing body of empirical literature on housing, particularly in developed countries, which offer mixed conclusions about the economic impact of house price changes. While many studies (e.g., Benjamin, Chinloy, and Jud, 2004; Case, Quigley, and Shiller, 2005; Carrol, Otsuka, and Slacalek, 2006; Campbell and Cocco, 2007; Kishor, 2007; Bostic, Gabriel, and Painter, 2008) substantiate the consumption effect of house price changes, there is some evidence that house price inflation is not favorable to consumer optimism. These studies include Phang (2004), Koivu (2010), and Song (2010). According to Phang (2004), the liquidity constraints of homeowners might be the reason why house price inflation in Singapore does not affect consumption. Housing being a risky asset with uncertain value, households are not willing to use housing equity to finance consumption. This interpretation is in line with the findings by Song (2010) that the existence of transaction costs halts the conventional comovement between housing and consumption. Additionally, the positive link between asset price and household consumption in China is not robust

Volume 20, Number 1, 2012 
due to the high volatility of the stock market (Koivu, 2010). Although these studies focus on consumption, their different results suggest that the housing effect is country specific.

Furthermore, the link between house prices and the macroeconomy is well established (Sutton, 2002; Tsatsaronis and Zhu, 2004; Stepanyan, Poghosyan, and Bibolov, 2010). However, with notable exceptions most of these studies are based on national data and ignore the issue of spatial dependence that might cause severe bias in the estimates. In effect, the work of Meen (1996) on the housing market in the United Kingdom has confirmed the high degree of parameter variation across the regions; invalidating thereby parameter homogeneity-based approaches such as aggregate national equations and panel estimations.

Given the dual causality between house prices and macroeconomic variables (Goodhart and Hofmann, 2008), one can conjecture that the impact and transmission mechanism of housing wealth also depend on business cycle trends. Demary (2009), therefore, highlights the need to consider output rather than consumption when assessing the effect of house price changes. This is because output summarizes the information such as investment and wages that may affect the transmission channel of house price variations. In fact, consumption being the main component of output, the rise in the demand for consumption goods following unexpected changes in house prices will push the GDP above its long-term steady state, ceteris paribus.

A study by Holly, Pesaran, and Yamaga (2010) investigated the link between house prices and output, using U.S. state-level panel data. They exploit newly developed techniques for the analysis of heterogeneous dynamic panels and show that house prices and per capita income converge in the long run. More interestingly, they find that spatial dependence matters in the U.S. housing market, and that the borrowing cost negatively affects real house prices. State-level population growth, however, is found to be positively related to changes in real house prices. Similar results are provided by Miller, Peng, and Sklarz (2011), who examine U.S. metropolitan statistics. They find the collateral effect to be stronger than the wealth effect, suggesting that financially constrained households are more likely to borrow against sustainable house price changes. Both studies apply the Common Correlated Effects (CCE) estimator, which controls for heterogeneity and spatial dependence.

However, these findings cannot be generalized to the developing countries since housing is country specific and crucially depends on the level of development. Moreover, the choice of the appropriate method depends on the purpose and characteristics of the data-generating process (Smith and Fuertes, 2008). For instance, the CCE estimator is not appropriate for short panels (Pesaran, 2006) and does not allow cross-sectional comparison since the estimation focuses on the average value of the parameter vector of the slope coefficients. On the other hand, Podesta (2002) points out that seemingly unrelated regression (SUR) represents an appropriate tool for comparative studies. Suitable for panel time series, this framework offers the possibility to link the causal effect within cross-sections to characteristics that vary across units. 
Therefore, this study makes the following contributions to the literature. First, it conducts a case study in a developing country on the basis of regional data, which provide more informative results. This is the first such attempt for South Africa. Second, the methodology employed allows for cross-provincial comparison by considering both heterogeneity and spatial dependence. Examining the housing market as a series of interconnected provincial markets rather than as a national aggregate amounts to capturing spatial structure as well as a provincial adjustment mechanism such as wages and migration (Meen, 1996).

In contrast to previous studies, this study offers a comparative analysis in terms of cross-provincial variations using SUR, which better fits relative thin panels. The studies above make important contributions by analyzing housing within a framework that addresses common factors including spatial dependence in large panels. However, they do not answer whether the impact and transmission mechanism of house price changes differ across cross-sections, whereas the present study tries to answer this question.

\section{Preliminary Data Analysis}

This study compiles regional data for nine provinces in South Africa during the period between 1996 and 2010 (i.e., $T=15$ and $N=9$ ). The choice of the data set is constrained by the availability of regional data, which start in 1996. Although there seems to be consensus among growth economists that annual data might not be ideal for statistical inference, Bond, Leblebicioglu, and Schiantarelli (2010) provide meaningful conclusions on growth analysis using annual variables. Based on available data and following Bond, Leblebicioglu, and Schiantarelli (2010), this study uses six annual time series: (1) per capita GDP, (2) house prices (HP), (3) personal income (PI), (4) population (POP), (5) the unemployment rate (UR), and (6) the number of buildings plans passed (BP), which is used as a proxy for the number of construction permits. Apart from house prices, ${ }^{1}$ obtained from Allied Bank of South Africa (ABSA), ${ }^{2}$ and buildings plans passed, derived from Statistics South Africa, the remaining four variables are provided by the Regional Explorer database maintained by Global Insight South Africa. Data on the Consumer Price Index (CPI) is extracted from the International Monetary Fund's database, which is used to obtain real terms for per capita GDP, house prices, and personal income.

Personal income, population, the unemployment rate and number of buildings plans passed are included as control variables to alleviate the reverse causation from economic growth to house prices. It is reasonable to argue that the impact of GDP on household income involve housing demand through its effect on local demographic conditions, such as migration and population changes (Ortalo-Magne and Rady, 2004). Therefore, personal income and population are used to capture this effect of GDP. Similarly, the impact of GDP on regional labor market conditions might affect both the demand for and supply of housing due to the resulting labour force migrations. Therefore, labor market conditions are proxied by unemployment rate (Clayton, Miller, and Peng, 2010). Furthermore, it is standard to control for housing construction

VOLUMe 20, Number 1, 2012 
as changes in economic performance contribute to house price changes prompted by the volume of housing transactions. As a result, the number of building plans passed is included in the regression. Accounting for all these control variables is likely to isolate the effect of the exogenous component of house prices caused by GDP.

The initial inspection of the data shows a strong comovement between per capita GDP and house prices, suggesting that they are positively related (Exhibit 3). However, in order to draw efficient conclusions, this relation needs to be assessed based on an econometric modeling. Since the asymptotic properties of standard panel estimators rely on whether time series are stationary or not, determining the order of integration of variables becomes important.

Exhibit 4 reports the results of the Im, Pesaran, and Shin (2003) (IPS) ${ }^{3}$ test, which is consistent in the presence of both heterogeneity and serial correlation. As mentioned earlier, provided that regions in the sample share some similar features, cross-section dependence is more likely to be present. Moreover, the size of the panel $(N=9)$ does not allow consideration of other alternatives such as cross-section IPS (CIPS), which has been shown to encounter under-size distortion (Hashiguchi and Hamori, 2010).

For a particular variable $y$, the starting point for the IPS test is a set of Augmented Dickey-Fuller (ADF) regressions of the following form:

$$
\Delta y_{i t}=\alpha_{i}+\beta_{i} y_{i, t-1}+\sum_{j=1}^{k} \phi_{i j} \Delta y_{i, t-j}+\lambda_{i} t+u_{i t} \text {, }
$$

where $\alpha_{i}$ and $\beta_{i}$ are panel-specific intercept and slope, respectively, $t$ is the time trend, and $u_{i t}$ the residuals assumed to be normal independently distributed for all crosssection $i$ with heterogeneous variances across panels.

The average $t$-statistic of these regressions is thereafter used to compute the IPS test as follows:

$$
\operatorname{IPS}=\frac{\sqrt{N}(\bar{t}-E(\bar{t}))}{\sqrt{\operatorname{var}(\bar{t})}} .
$$

All the variable levels exhibit non-stationarity. Only the variable $P O P$ is stationary without trend. However, it becomes non stationary when allowing for a time trend. This is plausible as the demographic boom is one of the major characteristics of developing nations. These results indicate that the null hypothesis of a panel unit root cannot be rejected, justifying the need to transform the data. Therefore, first differences of the log values of the variables are used rather than their log levels, except for the unemployment rate, for which only the first difference of the variable is used. The transformed data are denoted as: $g d p, h p, p i, p o p, b p$, and $u r$, which respectively stand for the growth rates of GDP, HP, PI, POP, BP, and the changes in UR. 


\section{Exhibit 3}

Per Capita GDP and House Prices

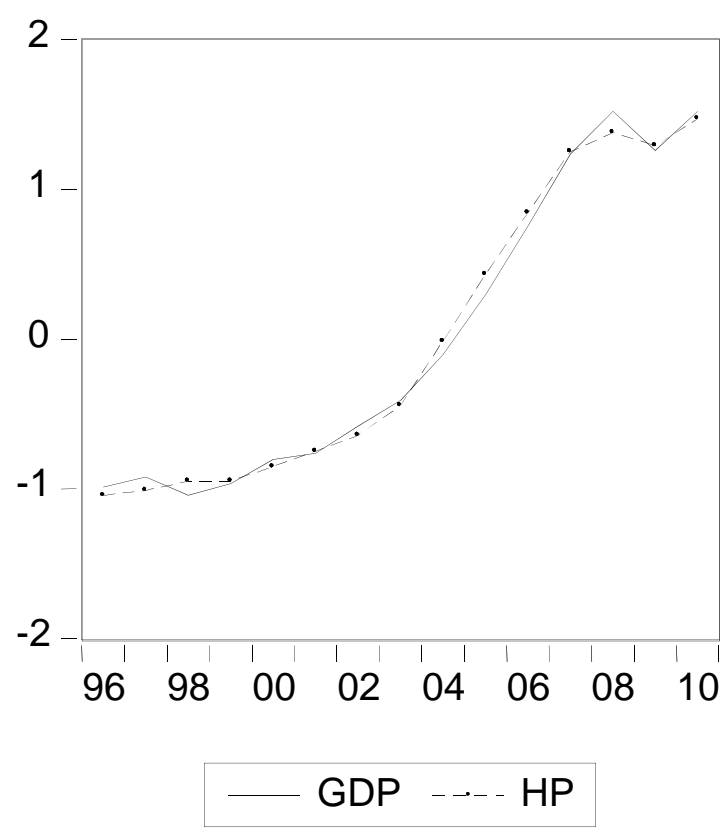

Per Capita

Growth Rate

of GDP

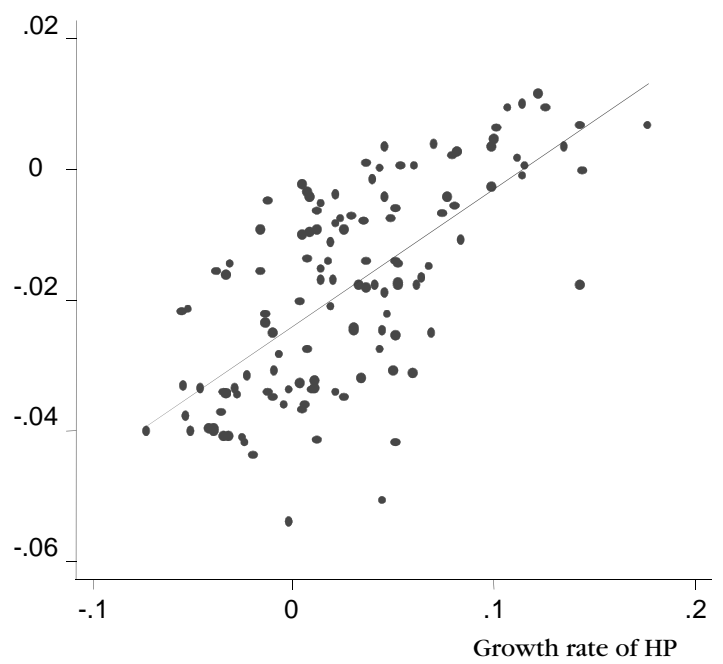

Notes: Upper panel shows normalized (transformed to same scale) real per capita GDP and real HP across regions. Lower panel shows OLS regression line between the per capita growth rate of GDP and the growth rate of HP across regions. 


\section{Exhibit 4 \\ IPS Unit Root Test Results}

\begin{tabular}{lllllll}
\hline & \multicolumn{1}{l}{ Variables } & & & & \\
\cline { 2 - 7 } & GDP & HP & \multicolumn{1}{l}{$P$} & \multicolumn{1}{l}{ POP } & UR & \multicolumn{1}{c}{$B P$} \\
\hline With trend & -2.06 & -1.40 & -1.69 & -0.12 & -2.39 & -2.28 \\
Without trend & -1.30 & -0.47 & 0.29 & -15.9 & -1.97 & -1.91 \\
\hline
\end{tabular}

Notes: Under the null hypothesis that all panels contain a unit root, we have $\alpha_{i}=0$ for all $i$. The alternative is that the fraction of panels that follow stationary processes is nonzero (i.e., as $N$ tends to infinity, the fraction $N 1=N$ converges to a nonzero value, where $N 1$ is the number of panels that are stationary). Critical values with trend are: $-2.88,-2.66$, and -2.54 at $1 \%, 5 \%$, and $10 \%$, respectively. Critical values without trend are: $-2.24,-2.02$, and -1.90 at $1 \%, 5 \%$, and $10 \%$ respectively.

Exhibit 5 summarizes the six time series across regions. Although the correlation between $g d p$ and $h p$ is positive and significant, both $g d p$ and $h p$ are significantly correlated to the regional control variables (personal income, population, total residential buildings, and the unemployment rate.). This justifies the importance of controlling for these variables in order to alleviate the reverse causation from $g d p$ to $h p$.

\section{EMPIRICAL Methodology}

The empirical analysis is based on panel time series modeling since the time dimension is dominant. Besides the wide benefits of panel data, ${ }^{4}$ panel time series can address the issues of heterogeneity and endogeneity in relatively thin panels. In addition, it is usual to assume the absence of cross-section dependence in panels but Smith and Fuertes (2008) assert that such assumption appears restrictive for many applications in macroeconomics and finance. Spatial econometrics suggest a natural way to characterise dependence in terms of distance. However, for most economic problems there is no obvious distance measure (Baltagi, 2008). Panel time series on the other hand, offer a variety of tools designed to deal with cross-sectional dependence; the choice of the method depending on purpose and characteristics of the data-generating process.

Recall that, although all the provinces in South Africa are subject to the same monetary and fiscal policies, political and legal environments, as well as financial market conditions, it is worth noting that the effects of macroeconomic shocks on the housing market might be of different magnitude across provinces. Furthermore, labor mobility and lower house prices in certain provinces may provide an incentive to migrate. In addition, there are notable differences among provinces in the country as far as the housing market is concerned. These differences include population density, human capital, and land availability among others. Given the importance of 


\section{Exhibit 5}

Data Summary

\begin{tabular}{|c|c|c|c|c|c|c|}
\hline & $g d p$ & $h p$ & pi & pop & $u r$ & $b p$ \\
\hline \multicolumn{7}{|c|}{ Panel A: Means, medians, and standard deviations } \\
\hline Mean & $-0.042^{*}$ & $0.062^{*}$ & $0.018^{*}$ & $0.011^{*}$ & $0.023 *$ & -0.016 \\
\hline Median & $-0.040^{*}$ & $0.049 *$ & $0.010 *$ & $0.011^{*}$ & 0.010 & -0.011 \\
\hline Std. Dev. & $0.036^{*}$ & $0.117^{*}$ & $0.034^{*}$ & $0.005^{*}$ & $0.087^{*}$ & $0.42^{*}$ \\
\hline \multicolumn{7}{|c|}{ Panel B: Correlation matrix } \\
\hline$g d p$ & 1 & & & & & \\
\hline$h p$ & $0.681 *$ & 1 & & & & \\
\hline pi & 0.819* & $0.518^{*}$ & 1 & & & \\
\hline pop & -0.153 & 0.034 & $-0.345^{*}$ & 1 & & \\
\hline$u r$ & $-0.412^{*}$ & $-0.2176^{*}$ & $-0.428 *$ & $0.323^{*}$ & 1 & \\
\hline$b p$ & $0.186^{*}$ & $0.2435^{*}$ & 0.161 & 0.112 & 0.098 & 1 \\
\hline
\end{tabular}

Notes: Panel A shows the cross regional averages of the means, medians, and standard deviations of the six variables (in log differences form). Panel B displays the cross regional average correlations among all the variables.

* Significant at the $5 \%$ level.

heterogeneity in spatially distributed housing markets, the hypothesis proposed here is that real income differs among provinces because of variations in real house prices.

The issue of heterogeneity is common in dynamic time series panels. It arises because of misspecification when assuming homogeneity across units. As a result, the regressors are correlated to the lagged dependent variable since the disturbance term is serially correlated. Two solutions are frequently suggested to deal with this problem. One can either use the Fixed Effect (FE) model or the Random Coefficient (RC) model. Although both models allow for cross-section individual effects, the FE model estimates might not be appropriate as slope coefficients are assumed to be homogeneous. The RC estimator, which considers the heterogeneity of both intercepts and slopes, is designed to address this inconsistency. More specifically, the baseline model is given by:

$$
g d p_{i t}=\alpha_{i}+\beta h p_{i t}+\delta^{\prime} x_{i t}+\lambda g d p_{i(t-1)}+\varepsilon_{i t} \quad i=1, \ldots, N ; t=1, \ldots, T,
$$

where $\alpha_{i}$ is a the regional fixed effect; $g d p_{i t}$ and $h p_{i t}$ are, respectively, the log differences of the regional GDP and house prices; $x_{i t}$ is a vector of control variables including log differences of personal income, population, the unemployment rate, and the $\log$ difference of the number of building plans passed; and $\varepsilon_{i t}$ is the error term.

The major attraction of the FE estimator is its ability to control for all region-specific characteristics, thereby alleviating potential sources of bias. This method consists of differencing out the individual variability across regions; the intuition being that within-variation can eliminate much of the error variance. Thus, the FE estimator 
results in a pooled Ordinary Least Squares (OLS) estimator on the differenced (demeaned) equation and provides unbiased estimates under a strict exogeneity assumption. However, disregarding between-variation can yield biased standard errors that may in turn lead to wrong inference. Differently from the FE model, which assumes random intercepts $\alpha_{i}$ and homogeneous slopes $\beta$, the RC model treats all parameters as random. Since it uses both within and between-variations, the RC model has less sampling variability than the FE model (Baltagi, 2008). The RC estimator proposed by Swamy and Tavlas (1995) can be interpreted as a Generalized Least Square (GLS) estimator that is a weighted average of the time series $\hat{\beta}_{i}$ estimates of different regions.

Specifically, the above equation takes the form:

$$
g d p_{i t}=\alpha_{i}+\beta_{i} h p_{i t}+\delta^{\prime} x_{i t}+\lambda g d p_{i(t-1)}+\varepsilon_{i t} .
$$

Note that both the $\mathrm{FE}$ and $\mathrm{RC}$ estimators provide consistent estimates under the assumption of orthogonality of the error term which, however, seems unrealistic for several reasons. First, some omitted variables included in the disturbances may be correlated with house prices. Second, Stepanyan, Poghosyan, and Bibolov (2010) argue that dynamics of fundamentals such as GDP, remittances, and external financing lead house price fluctuations. Hence, the independent variable (house prices) in the model appears to be determined simultaneously along with growth. Third, measurement errors are frequent in most empirical studies. These reasons raise the issue of endogeneity and the Hausman $\operatorname{test}^{5}(P>|t|=0.000)$ could not reject this assumption.

The SYSTEM-Generalised Method of Moments (SYS-GMM) estimator proposed by Arellano and Bover (1995) and Blundell and Bond (1998) is popular in addressing the problem of endogeneity. This method consists of controlling for a number of instruments in order to improve the efficiency of the estimates. To account for the existence of weak instruments, SYS-GMM makes available a large set of instruments that include the moment conditions for the first-difference GMM, as well as the extra moment conditions for the model in levels. However, this estimator is consistent for large samples and can be inconsistent if all the available instruments are being used (Hayakawa, 2006). The current study uses the small-sample adjustment provided by Windmeijer (2005). Furthermore, to avoid overfitting, the number of instruments is carefully controlled and "internal" instruments are used that only include lags of the instrumented variable $(h p)$.

Formally, the following specification is estimated:

$$
\Delta g d p_{i t}=\alpha \Delta h p_{i t}+\delta^{\prime} \Delta x_{i t}+\lambda \Delta g d p_{i(t-1)}+\Delta \varepsilon_{i t} .
$$

Although SYS-GMM might help to mitigate the issue of endogeneity, it is unable to alleviate the bias due to the spatial effect and its implications for parameters consistency. In fact, despite regional variations in economic development, GDP in one region can be affected by not only local house price changes but also house prices changes in other regions. Moreover, house prices might be correlated across regions 
and thus have spatial effect. This justifies the need to consider an error componentbased approach.

The Feasible Generalized Least Squares (FGLS) test does not impose any restrictions on the error structure. This procedure allows for autocorrelation within panels, crosssectional correlation, and/or heterocedasticity across units. It is similar to a random effects model in which the regression disturbances comprise three dimensions: one component associated with time, another associated with space, and the third associated with both time and space (Podesta, 2002). Furthermore, a Seemingly Unrelated Regression (SUR) is considered in order to link the differences in the economic impact of house prices within regions to characteristics that vary across regions. It is a system of individual regressions in which cross-equation errors are allowed to be correlated. Thus, FGLS can be interpreted as a pooled SUR in which estimates represent the average value of the regional coefficients since they vary across regions.

More precisely, by stacking the observations in the $t$ dimension, let $G D P_{t}=$ $\left[g d p_{1 t}, \ldots, g d p_{N t}\right]^{\prime}, H P_{t}=\left[h p_{1 t}, \ldots, h p_{N t}\right]^{\prime}, X_{t}=$ block-diagonal matrix with $x_{1 t}, \ldots, x_{N t}$ on its diagonal, $U_{t}=\left[\varepsilon_{1 t}, \ldots, \varepsilon_{N t}\right]^{\prime}$, the model has the following SUR representation:

$$
G D P_{t}=\alpha_{t}+\beta H P_{t}+\delta^{\prime} X_{t}+\lambda G D P_{(t-1)}+U_{t}
$$

where $U_{t}$ represents the contemporaneous cross-equation errors.

\section{ESTIMATION RESUltS}

This section first starts off with aggregated results. Four models, namely, the FE, RC, SYS-GMM, and FGLS estimators, are employed to estimate the economic effect of house price fluctuations. Based on a series of assessments on model diagnostics, the model with cross-section dependence appears the most appropriate. Cross-regional analysis is then used to present parameter estimates that vary across regions. The second interest consists of disaggregating the economic effect of the different components of house price changes.

\section{AGGREGATE EFFECT OF HOUSE PRICE CHANGES ON ECONOMIC GROWTH}

Exhibit 6 reports the results of four different estimators. In all the regressions, estimates for the coefficient of house price changes are positive and significant, which is consistent with the theoretical effect of house prices on economic growth. Nevertheless, there are noticeable differences among these estimators and it is useful to understand the source of these differences. The first regression, FE, which ignores the heterogeneity of slopes, finds no significant relation between GDP growth rate and three of the four control variables, notably population growth rate, unemployment rate, and changes in building plans passed. Although the RC regression accounts for the heterogeneity of slopes, its results do not really differ from the FE estimates. This is not surprising since both $\mathrm{FE}$ and $\mathrm{RC}$ are subject to the well-known Nickell bias when applied to short panel time series. However, the $F$-test $(\operatorname{Pr}>F=0.0362)$ and

Volume 20, Number 1, 2012 


\section{Exhibit 6}

\section{Estimates of House Prices on Economic Growth}

\begin{tabular}{|c|c|c|c|c|}
\hline$g d p$ & $\mathrm{FE}$ & $\mathrm{RC}$ & SYS-GMM & FGLS \\
\hline$h p$ & $0.086 * * *$ & $0.082 * *$ & $0.105^{*}$ & $0.827 * * *$ \\
\hline$p i$ & $0.727 * * *$ & $0.747 * * *$ & 0.489 & $0.383^{* * *}$ \\
\hline pop & 0.784 & 1.275 & $-3.42 * *$ & $-3.677^{* * *}$ \\
\hline$u r$ & -0.021 & -0.015 & 0.042 & -0.014 \\
\hline$b p$ & 0.002 & 0.001 & $0.012^{* *}$ & $0.005^{* * *}$ \\
\hline$g d p_{-1}$ & $-0.137^{*}$ & $-0.216^{*}$ & $-0.24^{*}$ & $-0.352^{* * *}$ \\
\hline $\mathrm{F}$ test & $(\operatorname{Pr}>F=0.036)$ & & & \\
\hline Wald test & & $\left(\operatorname{Pr}>\chi^{2}=0.000\right)$ & & $\left(\operatorname{Pr}>\chi^{2}=0.000\right)$ \\
\hline Sargan test & & & $\left(\operatorname{Pr}>\chi^{2}=1.000\right)$ & \\
\hline Arellano-Bond test & & & $(\operatorname{Pr}>Z=0.46)$ & \\
\hline
\end{tabular}

Notes: This table shows regressions of per capita $g d p$ on the house prices appreciation $(h p)$ controlled by regional variables: personal income (pi), population (pop), unemployment rate (ur), and building plans passed $(b p)$, including the lag dependent variable $g d p_{-1}$ to account for dynamics. The SYS-GMM estimates are corrected for small sample bias as in Windmeijer (2005).

* Significant at the $10 \%$ level.

** Significant at the $5 \%$ level.

*** Significant at the $1 \%$ level.

Wald test $\left(\operatorname{Pr}>\chi^{2}=0.000\right)$ illustrate some evidence of country fixed effects, and heterogeneity of intercepts and slopes, which rationalizes the use of FE and RC estimators as benchmarks in this instance.

In view of the above arguments, the FGLS estimators are consistent regardless of house price changes being endogenous. This substantiates the importance of allowing for cross-sectional dependence. The coefficient of house price changes is now significantly larger since the residual has been purged with the contemporaneous cross-equation error correlations. A positive shock in the housing market is likely to increase the economic growth in South Africa. Note that the lag dependent variable is found to be significant and negative, suggesting a conditional convergence across regions. In other words, poorer regions are expected to catch up with richer ones. Regional-level population growth has a significant and negative effect on per capita GDP growth, which is unsurprising given the high level of unemployment in developing countries.

\section{CROSS-REGIONAL DEPENDENCE ANALYSIS}

The potential importance of regional dependence is inspected based on the Lagrange Multiplier tests for the diagonality of the cross-equation error covariance matrix developed by Breusch and Pagan (1980). This approach assumes one particular form of spatial dependence: the spatial error model, which is well addressed in the SUR framework. This estimator further helps to improve the efficiency of the individual 
regression estimates by allowing cross-equation residuals to be correlated. The results are reported in Exhibit 7. Panel A provides strong evidence that house price changes affect economic growth and that the effects vary across provinces. For instance, the effect of house price changes in North West is about three times stronger than in Western Cape and KwaZulu-Natal. Similarly this causality in Free State, Limpopo, Gauteng, and Northern Cape is, respectively, about 2.3, 2, 1.5, and 1.3 times stronger than Western Cape and KwaZulu-Natal. The Breusch-Pagan test of independence $(\operatorname{Pr}=0.000)$ rejects the null hypothesis of independence, indicating the importance of cross-provincial correlation.

Panel B of Exhibit 7 provides the appropriate test for each province: the higher the correlation coefficient, the stronger the spatial dependence. In no province does spatial errors independence hold on the basis of correlation matrix residuals. Again, this appears to confirm the spatial interactions in the South African regional housing markets. Spatial dependence is omnipresent; the degree of dependence in the Western Cape is particularly noticeable, with higher correlation with almost all provinces. For instance, the house price shock originating in Western Cape spreads in six out of nine regions. Note that it is not consistently the case that dependence is related only to neighboring locations. For example, Limpopo has links with the Eastern Cape, whereas Gauteng is related to Western Cape, Eastern Cape, and KwaZulu Natal. This raises the inadequacy of the simple binary spatial weights matrices and matrices based on distance decay. It is also important to highlight that practically all the correlation residuals are positive, suggesting the absence of planning restrictions, which might force builders to migrate elsewhere (Meen, 1996).

Spatial dependence is related to spatial convergence, which implies a stable long-run relationship between house prices in the regions. Although not shown, if house price changes in one region affect the economy in other regions, there is also the possibility of spatial convergence in house prices. In effect, the growth convergence hypothesis cannot be rejected in this instance; the average coefficient of $g d p_{-1}$ being negative and significant $(-0.352)$. Given the reverse causation from growth, migration and job market conditions may act as regional equilibrium mechanisms leading to house price convergences. This interpretation is in line with the evidence of "ripple effects" found by Das, Gupta, and Kaya (2010) and Balcilar, Beyene, Gupta, and Seleteng (forthcoming) in the housing market of metropolitan areas of South Africa.

\section{ECONOMIC EFFECT OF THE DIFFERENT COMPONENTS OF HOUSE PRICES}

Recall that there are two main mechanisms that drive the economic effect of house price changes. A better understanding of these mechanisms requires a distinction between the predictable component, which captures the collateral effect $(h p c),{ }^{6}$ and the unpredictable component, which denotes the wealth effect $(h p w)$. The predictable and unpredictable components are proxied respectively by the fitted values and the residuals of the regression of house price changes on an intercept term and the instrumental variables. These instruments include twice lagged $g d p, h p, p o p$, and $p i$. Note that the regression is conducted for each region separately. The descriptive statistics are summarized in Exhibit 8. While the wealth effect appears to be of

Volume 20, Number 1, 2012 


\section{Seemingly Unrelated Regression Estimates}

\begin{tabular}{|c|c|c|c|c|c|c|c|c|c|}
\hline & $\begin{array}{l}\text { Western } \\
\text { Cape }\end{array}$ & $\begin{array}{l}\text { Eastern } \\
\text { Cape }\end{array}$ & $\begin{array}{l}\text { Northern } \\
\text { Cape }\end{array}$ & Free State & KwaZulu-Natal & North West & Gauteng & Mpumalanga & Limpopo \\
\hline \multicolumn{10}{|c|}{ Panel A: Regional regressions of the growth rate of $g d p$} \\
\hline$h p$ & $0.087 * *$ & $0.129 * * *$ & $0.153^{* * *}$ & $0.195^{* * *}$ & $0.084^{* *}$ & $0.258 * * *$ & $0.157 * * *$ & $0.123^{* * *}$ & $0.162 * * *$ \\
\hline pi & $0.379 * *$ & $0.302 *$ & $0.625^{* * *}$ & -0.021 & $0.779 * * *$ & $0.247^{* *}$ & $0.194^{*}$ & 0.045 & 0.089 \\
\hline pop & $-2.354 * * *$ & $-7.970 * * *$ & $-6.560 * * *$ & $-6.331 * * *$ & 0.412 & $-6.220 * * *$ & $-2.444 * * *$ & $-2.930 * * *$ & $-3.590 * * *$ \\
\hline ur & $-0.137^{* *}$ & -0.035 & $0.047^{*}$ & $-0.208 * *$ & -0.044 & $-0.129 * *$ & $-0.073^{*}$ & $-0.138 * * *$ & $0.118^{* *}$ \\
\hline bp & -0.0003 & $-0.022 * *$ & $-0.005^{* *}$ & 0.004 & 0.007 & $0.034 * * *$ & $0.018^{*}$ & $0.037^{* * *}$ & 0.012 \\
\hline$g d p_{-1}$ & -0.127 & -0.024 & -0.125 & $-0.974 * * *$ & -0.091 & $-0.950 * * *$ & $-0.357^{* *}$ & $-0.864 * * *$ & $-0.360 * *$ \\
\hline \multicolumn{10}{|c|}{ Breusch-Pagan test of independence: $\chi^{2}(36)=96.103(\operatorname{Pr}=0.000)$} \\
\hline \multicolumn{10}{|c|}{ Panel B: Correlation matrix of residuals } \\
\hline Western Cape & 1 & & & & & & & & \\
\hline Eastern Cape & 0.684 & 1 & & & & & & & \\
\hline Northern Cape & 0.534 & 0.468 & 1 & & & & & & \\
\hline Free State & 0.602 & 0.414 & 0.279 & 1 & & & & & \\
\hline KwaZulu-Natal & 0.693 & 0.289 & 0.524 & 0.423 & 1 & & & & \\
\hline North West & -0.325 & 0.014 & 0.387 & 0.171 & -0.121 & 1 & & & \\
\hline Gauteng & 0.693 & 0.748 & 0.351 & 0.488 & 0.567 & -0.092 & 1 & & \\
\hline Mpumalanga & 0.154 & 0.383 & 0.058 & 0.178 & 0.266 & 0.679 & 0.435 & 1 & \\
\hline Limpopo & 0.369 & 0.272 & 0.637 & -0.174 & 0.466 & 0.005 & 0.282 & 0.189 & 1 \\
\hline \multicolumn{10}{|c|}{$\begin{array}{l}\text { Notes: Panel A reports the SUR } \\
\text { * Significant at the } 10 \% \text { level. } \\
\text { ** Significant at the } 5 \% \text { level. } \\
\text { ** Significant at the } 1 \% \text { level. }\end{array}$} \\
\hline
\end{tabular}




\section{Exhibit 8 \\ House Price Changes Disintegration}

\begin{tabular}{llll}
\hline & $h p$ & $h p c$ & $h p w$ \\
\hline Panel A: Means, medians, and standard deviations & & \\
\hline Mean & $0.062^{*}$ & $0.072^{*}$ & 0.000 \\
Median & $0.049^{*}$ & $0.069^{*}$ & 0.009 \\
Std. Dev. & $0.117^{*}$ & $0.079^{*}$ & $0.091^{*}$ \\
\hline Panel B: Correlation matrix & & & \\
\hline$h p$ & 1 & & \\
$h p c$ & $0.656^{*}$ & 1 & 1 \\
$h p w$ & $0.755^{*}$ & -0.000 & \\
\hline
\end{tabular}

Notes: This table reports summary statistics for different components of house price inflation. Panel A reports the cross-regional averages of the means, the medians, and the standard deviations. Panel B reports the cross-regional average correlations among the components. $T$-tests are conducted for zero-means.

* Significant at the $5 \%$ level.

negligible importance, the collateral effect appears to validate the hypothesis that households are expected to borrow more against house price inflation. The reason is because the wealth effect corresponds to regression residuals that sum to zero. Adequate econometric tools are therefore required to examine the true causality.

Having established the distinction between collateral and wealth effects, the interest is now focused on the economic magnitude of each component of house price changes. These estimates are computed first for the average economic effect across regions. Thereafter, SUR estimators are used to account for cross-sectional variation of the economic effect. The results are reported in Exhibit 9.

As observed from Exhibit 9, predictable and unpredictable components of house price changes are positive, ${ }^{7}$ although not all significant. The pooled estimators show that the wealth effect of house price changes across regions are stronger than the collateral effect; the coefficients of the two effects being respectively, 0.149 and 0.101 , in the preferred model (FGLS). This suggests that the aggregate borrowing facility is not the relevant variable in South Africa. In effect, the collateral effect is based on the intuition that housing wealth is an important borrowing collateral and hence, the economic impact of house prices is expected to relate to the borrowing constraints of homeowners. In other words, the collateral effect is stronger when households are more constrained and the wealth effect is higher when households are less constrained. ${ }^{8}$

For the cross-regional variation analysis, the results are mixed. In terms of magnitude, the wealth effect is dominant in Northern Cape, North West, Gauteng, and Limpopo, indicating that households are not affected by the collateral value of their houses since 


\section{Exhibit 9}

Economic Impact of Different Components of House Prices

\begin{tabular}{lcc}
\hline & $h p c$ & $h p w$ \\
\hline Panel A: Average impact across regions & & \\
\hline FE & $0.088^{* * *}$ & $0.110^{* * *}$ \\
RC & 0.056 & $0.094^{* *}$ \\
SYS-GMM & 0.423 & 0.489 \\
FGLS & $0.101^{* * *}$ & $0.149^{* * *}$ \\
\hline Panel B: Regional impact & & \\
\hline Western Cape & $0.291^{* * *}$ & $0.183^{* * *}$ \\
Eastern Cape & $0.163^{* * *}$ & $0.089^{*}$ \\
Northern Cape & $0.121^{* * *}$ & $0.221^{* * *}$ \\
Free State & 0.106 & $0.097^{*}$ \\
KwaZulu-Natal & $0.106^{* *}$ & 0.042 \\
North West & -0.055 & $0.134^{* * *}$ \\
Gauteng & $0.184^{* *}$ & $0.234^{* * *}$ \\
Mpumalanga & $0.174^{* * *}$ & $0.055^{* *}$ \\
Limpopo & $0.269^{* *}$ & $0.357^{* * *}$ \\
Breusch-Pagan test of independence: $\chi(36)$ & $102.44(P r=0.000)$ & \\
\hline Notes: Panel A reports the pooled effect of each component of the house price changes. Panel B & \\
displays the effect of each component of house price changes for different regions. & \\
* Significant at the 10\% level. & & \\
** Significant at the 5\% level. & & \\
*** Significant at the 1\% level. & & \\
\hline
\end{tabular}

they are less constrained. Also, as indicated in Campbell and Cocco (2007), the collateral and wealth effects are not mutually exclusive except in Free State, KwaZuluNatal, and North West.

On the other hand, the collateral effect dominates in Western Cape, Eastern Cape, KwaZulu-Natal, and Mpumalanga, substantiating the hypothesis that at the regional level, households more likely borrow against house price inflation (Miller, Peng, and Sklarz, 2011). Besides the inability for South African households to save (Luus, 2002), these provinces are dominated by low-income households that are more exposed to financial constraints. While Eastern Cape is the poorest province in South Africa (Baiyegunhi, Fraser, and Darroch, 2010), the presence of poor households in KwaZulu-Natal is not surprising since local economic development is essentially driven by the small, medium, and micro enterprises that are also subjected to financial constraints (Rankhumise and Rugimbana, 2010).

Moreover, although Western Cape and Mpumalanga inherit socio-economic benefits, their increasing level of inequality (Bhorat and Van der Westhuizen, 2005) favorable to poverty might be the reason why constrained households are more prominent in these provinces than unconstrained households. Regional variations are likely due to the socio-economic imbalances among provinces. 


\section{Conclusion}

This paper investigates the economic impact of house prices in a panel made up of nine South African provinces over fifteen years where there is a significant spatial dependence. Different estimation techniques are applied to account for heterogeneity, endogeneity, and spatial dependence in analyzing house prices within a panel data context. After addressing these econometric issues, the results provide strong evidence that house price changes affect regional economic growth and that the effects vary across regions.

The causation from house price changes to economic growth channels through the collateral effect and the wealth effect. The findings reveal that the wealth effect of house prices is stronger than the collateral effect at the aggregate level, indicating that homeowners are more likely to raise their desired consumption as house prices increase. Conversely, at the regional level, the collateral effect dominates in four provinces: Western Cape, Eastern Cape, KwaZulu-Natal, and Mpumalanga. In these regions, homeowners are more likely to borrow against house price appreciation to increase their actual consumption. From a policy perspective, these findings suggest that the monetary authority might want to stimulate the economy by relaxing borrowing constraints in regions where the collateral effect is dominant (Miller, Peng, and Sklarz, 2011). On the other hand, this policy might not be efficient at the aggregate level since a fall in house prices is more likely to lead to an economic recession due to the wealth effect. However, as mentioned earlier, the two effects are not clearly separated in a way that provides sufficient evidence that the economic impact of house prices is due to wealth effect or collateral effect. This result is in line with Campbell and Cocco (2007), who assert that the two effects are not mutually exclusive.

In general, there is overwhelming evidence of a positive impact of house prices on provincial-level growth in South Africa. This finding relies on the consumption effect of housing prices which is, however, not empirically supported by the analysis in this study. Therefore, a more rigorous empirical analysis of the spillover effects of house prices would provide further insights into house price dynamics in South Africa.

\section{ENDNOTES}

1. ABSA categorizes housing into three price segments: luxury (ZAR 3.5 million-ZAR 12.8 million), middle (ZAR 480,000-ZAR 3.5 million), and affordable (below ZAR 480,000 and area between 40 square meters-79 square meters). The middle segment is further categorized into three more segments based on sizes: large-middle (221 square meters-400 square meters), medium-middle (141 square meters-220 square meters), and small-middle (80 square meters-140 square meters). Additionally, house prices are also available for the entire middle segment. However, no house price data are available at the provincial level for the luxury and affordable sections. Hence, for provincial-level house price data, the house prices corresponding to the entire middle segment are used. This is understandable since the other provincial-level macro variables are not categorized based on the alternative sizes of the middle-segment.

2. ABSA is one of the leading private banks in South Africa.

Volume 20, Number 1, 2012 
3. Alternatives to the IPS test include Maddala and Wu (1999) and Levin, Lin, and Chu (2002), among others.

4. The advantages of panel data include: (1) efficiency gains and the possibility of estimating more complex dynamic models, (2) identifying unobserved effects such as differences in adjustment over units, and (3) mitigating multicollinearity problems.

5. The test is conducted in two steps: first the potential endogenous variable $(H P)$ is regressed on its instruments (its own lags and the other control variables). The residuals from this regression are then added in the main regression as an additional independent variable. Under the null hypothesis of exogeneity, the coefficient of this extra explanatory variable is expected not to be significant at the conventional level of significance.

6. Readers should be cautious that precautionary savings or myopic behavior might also be part of the predictable component of house price changes (Campbell and Cocco, 2007).

7. The coefficient of the collateral effect is negative in North West but not significant.

8. The empirical test was also conducted using the housing ratio proposed by Lustig and Van Nieuwerburg (2008). An an additional regressor (interaction between house price changes and housing collateral ratio) is added to the previous regressions; a negative sign being expected for the coefficient of the interaction term as households are less constrained when the housing collateral ratio is larger. However, the coefficient was found positive, substantiating the importance of the wealth effect. The estimation results are available upon request from the authors.

\section{REFERENCES}

Arellano, M. and O. Bover. Another Look at the Instrumental Variable Estimation of Errorcomponents Models. Journal of Econometrics, 1995, 68, 29-51.

Baiyegunhi, L.J.S., G.C.G. Fraser, and M.A.G. Darroch. Credit Constraints and Household Welfare in the Eastern Cape Province, South Africa. African Journal of Agricultural Research, 2010, 5:16, 2243-52.

Balcilar, M., A.D. Beyene, R. Gupta, and M. Seleteng. Ripple Effects in South African House Prices. Urban Studies, forthcoming.

Baltagi, B.H. Econometrics. Fourth edition. Berlin and Heidelberg Germany: Springer-Verlag, 2008.

Benjamin, J.D., P. Chinloy, and G.D. Jud. Real Estate versus Financial Wealth in Consumption. Journal of Real Estate Finance and Economics, 2004, 29, 341-54.

Bhorat, H. and C. Van der Westhuizen. Economic Growth, Poverty and Inequality in South Africa: The First Decade of Democracy. http://dev.absol.co.za/Presidency/docs/reports/ 15year_review/social/economic_growth.pdf, 2005.

Blundell, R. and S. Bond. Initial Conditions and Moment Restrictions in Dynamic Panel Data Models. Journal of Econometrics, 1998, 87, 115-43.

Bond, S., A. Leblebicioglu, and F. Schiantarelli. Capital Accumulation and Growth: A New Look at the Empirical Evidence. Journal of Applied Econometrics, 2010, 25: 1073-99.

Bostic, R., S. Gabriel, and G. Painter. Housing Wealth, Financial Wealth, and Consumption: New Evidence from Micro Data. University of Southern California Working Paper, 2008.

Breusch, T.S. and A.R. Pagan. The Lagrange Multiplier Test and its Applications to Model Specification in Econometrics. Review of Economic Studies, 1980, 47, 239-53.

Campbell, J.Y. and J.F. Cocco. How Do House Prices Affect Consumption? Evidence from Micro Data. Journal of Monetary Economics, 2007, 54:3, 591-621. 
Carroll, C.D., M. Otsuka, and J. Slacalek. How Large is the Housing Wealth Effect? A New Approach. NBER Working Paper No. W12746, 2006.

Case, K.E., J.M. Quigley, and J.R. Shiller. Comparing Wealth Effects: The Stock Market versus the Housing Market. Advances in Macroeconomics, 2005, 5:1, 1-34.

Clayton, J., N. Miller, and L. Peng. Price-volume Correlation in the Housing Market: Causality and Co-movements. Journal of Real Estate Finance and Economics, 2010, 40, 14-40.

Das, S., R. Gupta, and P.A. Kaya. Convergence of Metropolitan House Prices in South Africa: A Re-examination using Efficient Unit Root Tests. Applied Econometrics and International Development, 2010, 10:1, 173-88.

Das, S., R. Gupta, and P.T. Kanda. Bubbles in South African House Prices and Their Impact on Consumption. Journal of Real Estate Literature, 2011, 19:1, 71-92.

Demary, M. The Link between Output, Inflation, Monetary Policy and Housing Price Dynamics. MPRA paper No. 15978. http://mpra.ub.uni-muenchen.de/15978/, 2009.

Goodhart, C.A.E. and B. Hofmann. House Prices, Money, Credit, and the Macroeconomy. Oxford Review of Economic Policy, 2008, 24, 180-205.

Hashiguchi, Y. and S. Hamori. Small Sample Properties of CIPS Panel Unit Root Test under Conditional and Unconditional Heteroscedasticity. MPRA paper No. 24053. http://mpra.ub.unimuenchen.de/24053/, 2010.

Hayakawa, K. The Asymptotic Properties of the System GMM Estimator in Dynamic Panel Data Models when Both N and T are large. Hi-Stat, Discussion Paper No. 129, 2006.

Holly, S., M.H. Pesaran, and T. Yamaga. A Spatio-temporal Model of House Prices in the USA. Journal of Econometrics, 2010, 158, 160-73.

Holmes, M.K. How Convergent are Regional House Prices in the United Kingdom? Some New Evidence from Panel Data Unit Root Testing. Journal of Economic and Social Research, 2007, 9:1, 1-17.

Im, K.S., M.H. Pesaran, and Y. Shin. Testing for Unit Roots in Heterogeneous Panels. Journal of Econometrics, 2003, 115, 53-74.

Kishor, N.K. Does Consumption Respond More to Housing Wealth than to Financial Market? If So, Why? Journal of Real Estate Finance and Economics, 2007, 35:4, 427-48.

Koivu, T. Monetary Policy, Asset Prices and Consumption in China. Working Paper No. 1240, European Central Bank, 2010.

Levin, A., C.F. Lin, and C.S.J. Chu. Unit Root Tests in Panel Data: Asymptotic and FiniteSample Properties. Journal of Econometrics, 2002, 108, 1-24.

Lustig, H. and S. Van Nieuwerburg. How Much Does Household Collateral Constraint Regional Risk Sharing? University of Chicago Working Paper, 2008.

Luus, C. The ABSA Residential Property Market Database for South Africa-Key Data Trends and Implications. BIS papers no 21, 2002.

Maddala, G. and S. Wu. A Comparative Study of Unit Root Tests and a New Simple Test. Oxford Bulletin of Economics and Statistics, 1999, 61, 631-52.

Meen, G. Spatial Aggregation, Spatial Dependence and Predictability in the U.K. Housing Market. Housing Studies, 1996, 11:3, 345-73.

Miller, N., L. Peng, and M. Sklarz. House Prices and Economic Growth. Journal of Real Estate Finance and Economics, 2011, 42:4, 522-41.

Naude, W.A. and W.F. Krugell. Sub-national Growth Rate Differentials in South Africa: An Econometric Analysis. Regional Science, 2006, 85:3, 443-57.

Ortalo-Magne, F. and S. Rady. Housing Transactions and Macroeconomic Fluctuations: A Case Study of England and Wales. Journal of Housing Economics, 2004, 13, 287-303.

Pesaran, M.H. Estimation and Inference in Large Heterogeneous Panels with Multifactor Error Structure. Econometrica, 2006, 74, 967-1012. 
Phang, S.Y. House Prices and Aggregate Consumption: Do They Move Together? Evidence from Singapore. Journal of Housing Economics, 2004, 13, 101-19.

Podesta, F. Recent Developments in Quantitative Comparative Methodology: The Case of Pooled Time Series Cross-section Analysis. Discussion papers soc 3-02, 2002.

Rankhumise, M.E. and O.R. Rugimbana. Microenterprise Owner Perspectives on Performance: Insights from Selected Municipalities in Mpumalanga Province, South Africa. African Journal of Business Management, 2010, 4:16, 3500-07.

Smith, R.P. and A.M. Fuertes. Panel Time-series. cemap course. University of London, 2008.

Song, H.I. (2010). House Prices and Consumption. Job Market Paper, Department of Economics, The Ohio State University, 2010.

Sutton, G. Explaining Changes in House Prices. BIS Quarterly Review, September, 2002.

Stepanyan, V., T. Poghosyan, and A. Bibolov. House Price Determinants in Selected Countries of the Former Soviet Union. IMF Working Paper 2010-104, 2010.

Swamy, P.A.V.B. and G.S. Tavlas. Random Coefficient Models: Theory and Applications. Journal of Economic Surveys, 1995, 9:2, 165-96.

Tsatsaronis, K. and H. Zhu. What Drives Housing Price Dynamics: Cross Country Evidence. BIS Quarterly Review, Bank for International Settlements, March, 2004.

Windmeijer, F. A Finite Sample Correction for the Variance of Linear Efficient Two-step GMM Estimators. Journal of Econometrics, 2005, 126, $25-51$.

We would like to thank an anonymous referee for many helpful comments.

Beatrice D. Simo-Kengne, University of Pretoria, Pretoria, 0002, South Africa or simobeatrice@gmail.com.

Manoel Bittencourt, University of Pretoria, Pretoria, 0002, South Africa or manoel.bittencourt@up.ac.za.

Rangan Gupta, University of Pretoria, Pretoria, 0002, South Africa or rangan. gupta@up.ac.za. 